\title{
Compilation of 1:50,000 vegetation type map with remote sensing images based on mountain altitudinal belts of Taibai Mountain in the North-South transitional zone of China
}

\author{
YAO Yonghui ${ }^{1}$, SUONAN Dongzhu ${ }^{1,2}$, ZHANG Junyao ${ }^{1,2}$ \\ 1. State key Laboratory of Resources and Environment Information System, Institute of Geographic Sciences \\ and Natural Resources Research, CAS, Beijing 100101, China; \\ 2. University of Chinese Academy of Sciences, Beijing 100049, China
}

\begin{abstract}
The compilation of 1:250,000 vegetation type map in the North-South transitional zone and 1:50,000 vegetation type maps in typical mountainous areas is one of the main tasks of Integrated Scientific Investigation of the North-South Transitional Zone of China. In the past, vegetation type maps were compiled by a large number of ground field surveys. Although the field survey method is accurate, it is not only time-consuming, but also only covers a small area due to the limitations of physical environment conditions. Remote sensing data can make up for the limitation of field survey because of its full coverage. However, there are still some difficulties and bottlenecks in the extraction of remote sensing information of vegetation types, especially in the automatic extraction. As an example of the compilation of 1:50,000 vegetation type map, this paper explores and studies the remote sensing extraction and mapping methods of vegetation type with medium and large scales based on mountain altitudinal belts of Taibai Mountain, using multi-temporal high resolution remote sensing data, ground survey data, previous vegetation type map and forest survey data. The results show that: 1) mountain altitudinal belts can effectively support remote sensing classification and mapping of 1:50,000 vegetation type map in mountain areas. Terrain constraint factors with mountain altitudinal belt information can be generated by mountain altitudinal belts and 1:10,000 Digital Surface Model (DSM) data of Taibai Mountain. Combining the terrain constraint factors with multi-temporal and high-resolution remote sensing data, ground survey data and previous small-scale vegetation type map data, the vegetation types at all levels can be extracted effectively. 2) The basic remote sensing interpretation and mapping process for typical mountains is interpretation of vegetation type-groups $\rightarrow$ interpretation of vegetation formation groups, formations and subformations $\rightarrow$ interpretation and classification of vegetation types \& subtypes, which is a combination method of top-down method and bottom-up method, not the top-down or the bottom-up classification according to the level of mapping
\end{abstract}

Received: 2019-04-17 Accepted: 2019-06-20

Foundation: National Natural Science Foundation of China, No.41871350, No.41571099; Scientific and Technological Basic Resources Survey Project, No.2017FY100900

Author: Yao Yonghui (1975-), PhD and Associate Professor, specialized in GIS/RS application and mountain environment. E-mail: yaoyh@1reis.ac.cn 
units. The results of this study provide a demonstration and scientific basis for the compilation of large and medium scale vegetation type maps.

Keywords: vegetation type map; high resolution remote sensing data; mountain altitudinal belts; remote sensing interpretation; Taibai Mountain

\section{Introduction}

Before 1957, vegetation mapping in China was mainly focused on small-scale vegetation sketch maps and vegetation regionalization maps. In this period, the study of vegetation mapping was in the early stage of dispersion and spontaneity (CVMEC, 2007), and the representative atlas included Draft of Vegetation Regionalization in China (Qian et al., 1956) and Vegetation-soil Regionalization Map of China (Hou et al., 1956). After 1957, lots of wide field vegetation surveys and vegetation regionalization work were carried out successively all over China, and the theories and methods of vegetation mapping in Soviet Union were introduced into China, which enabled vegetation mapping research in China to reach a new relatively mature stage (CVMEC, 2007). The representative atlas in this period was 1:4,000,000 Vegetation Map of the People's Republic of China (Hou et al., 1979). In 1979, supported by the National Agricultural Commission, the National Science and Technology Commission and the Chinese Academy of Sciences, the Institute of Botany of the Chinese Academy of Sciences organized the national vegetation mapping community to establish the China Vegetation Map Editing Committee, which was directed by Hou Xueyu (later directed by Zhang Xinshi), and started to compile the 1:1,000,000 vegetation map of China. Since 1981, vegetation field surveys have been carried out in China, more than 250 vegetation experts have participated in the survey, and many academic conferences associated with vegetation mapping have been held. In 2000, the 1:1,000,000 China Vegetation Atlas (CVMEC, 2000) was published, which is the most detailed and accurate national vegetation map nowadays.

The above vegetation mapping efforts were made based on the traditional ground surveys which took a lot of manpower and were time-consuming. On the one hand, limited by computer technology and remote sensing technology at that time, the conditions for using remote sensing data to compile vegetation maps were still immature; on the other hand, the compilation of small-scale vegetation maps through ground survey could meet the social needs at that time. In the 21 st century, with the development of remote sensing technology, it has become very common to use remote sensing data for the studies of land use and land cover change, vegetation change, vegetation phenology monitoring and forest resource surveys in a large-scale. Liu et al. (1996, 2003a, 2003b, 2010) have built a national land use change database with satellite remote sensing data as the main information source and updated this database every five years using the same satellite remote sensing data source and the same data analysis methods. Combining NDVI with phenological information, decision tree method is usually used to monitor forest resources and extract vegetation information (Jia et al., 2014; Chen et al., 2016; Lei et al., 2016; Hu et al., 2017). For example, Chen et al. (2016) combined the multi-temporal Landsat images which had spectral and phenological information with radar data that possessed better forest structure information, and used the decision tree method to classify and identify tropical rain forest and rubber plantation in Hainan Island. Combining multi-temporal remote sensing images in growing season and non-growing 
non-growing season, Lei et al. (2016) realized automatic extraction of mountain forest types by decision tree method. Combining the spectral and texture features of HJ-1 CDD with the phenological features of MODIS time series data, Jia et al. (2014) used object-oriented classification method to extract forest vegetation types. These results showed that the classification methods with phenological characters could greatly improve the classification accuracy of forest types (Hu et al., 2016). In recent years, remote sensing collaborative inversion has become the research frontier. Based on Geographically Assisted Knowledge Base and multi-source remote sensing data, quantitative description and comprehensive inversion of spatial-temporal variation characteristic parameters of land surface can be carried out by remote sensing collaborative inversion. The information model and theoretical method system of spatial-temporal variable elements based on prior knowledge base can be established (Demir et al., 2013; Wu et al., 2014; Marsetic et al., 2015; Luo et al., 2017). Remote sensing collaborative inversion has strong application value in vegetation remote sensing mapping by taking advantage of the combination of spatial information and spectral features of multiple sensors.

With the development of remote sensing extraction technologies, the condition which using multi-source remote sensing big data to develop medium- and large-scale vegetation mapping has become matured. In Scientific and Technological Basic Resources Survey Project Comprehensive Scientific Investigation of the North-South Transitional Zone of China (2017FY100900), a series of comprehensive investigations on vegetation, soil, climate, hydrology and other resources in the region are carried out. One of the important tasks in this project is to compile the 1:250,000 vegetation type map of the Transitional Zone and the 1:50,000 vegetation type maps in four typical mountains using remote sensing data combined with field investigations. In addition, the North-South transitional zone has a particularly prominent position and significance in geo-ecological pattern in China. Under the background of global change, the compilation of medium and large-scale vegetation type maps in the transitional zone is very important for the in-depth study of the spatial-temporal variation rules of vegetation in the transitional zone (Liu et al., 2015; Zhang et al., 2018), and has great significance on revealing China's geo-ecological pattern and identifying the characteristics of China's geographical variation (Zhang et al., 2018). Therefore, as an example of the compilation of 1:50,000 vegetation type map, this paper explores and studies the remote sensing extraction and mapping methods of vegetation type with medium and large scales based on mountain altitudinal belts of Taibai Mountain, using multi-temporal high resolution remote sensing data, ground survey data, previous vegetation type map and forest survey data. The result of this paper will provide a demonstration for large-scale vegetation type mapping in the transitional zone.

\section{Vegetation outline of Taibai Mountain in Qinling Mountains}

Taibai Mountain is located in the central part of the Qinling Mountains in Shaanxi province $\left(107^{\circ} 41^{\prime} 23^{\prime \prime}-107^{\circ} 51^{\prime} 40^{\prime \prime} \mathrm{E}, 33^{\circ} 49^{\prime} 31^{\prime \prime}-34^{\circ} 08^{\prime} 11^{\prime \prime} \mathrm{N}\right)$. It is the southern boundary of the warm temperate zone and the northern boundary of the subtropical zone in China (Figure 1). The climate of Taibai Mountain is controlled by Mongolian cold air mass in winter and influenced by the Pacific subtropical high pressure belt in summer, which is characterized by the 
transition from north to south. The biological populations are also characterized by the transition from north to south and east to west. According to the classification of floristics of seed plant flora from China, plants of Taibai Mountain belong to pan-arctic botanical region, Sino-Japanese floristic subregion and central China floristic region (Xia, 2011). Temperate families, such as Compositae, Rosaceae, Ranunculaceae, Cyperaceae, Umbelliferae, Saxifragaceae and Polygonaceae, dominate the vegetation flora and composition of the study area. In addition, typical temperate or subtropical-temperate distribution, but mainly temperate distribution families are Pinaceae, Salicaceae, Aceraceae, Berberidaceae, Caprifoliaceae, Betulaceae, Liliaceae, Fagaceae, Campanulaceae and so on.

Due to the difference in climate, the mountain altitudinal belts on the north and south slopes of Taibai Mountain are different in the characteristics of the base belt and the distribution height of each altitudinal belt (Figure 2) (Fang and Gao, 1963; Li, 2007). The base belt of the north slope is deciduous broad-leaved forest represented by Quercus variabilis forest; the base belt of the south slope is deciduous broad-leaved forest with evergreen species such as small Cyclobalanopsis glauca and Quercus acrodonta (Yue, 2015). Furthermore, the Quercus liaotungensis forest exists on the north slope, but not on the south slope. Quercus liaodongensis is a typical flora of north China and rarely grows on the south slope of Qinling Mountains except in Fengxian county, the west Qinling Mountains. The appearance of Quercus liaodongensis forest is one of the obvious signs of the difference between mountain altitudinal belts on the north and south slopes in Qinling Mountains (Yue, 2015).

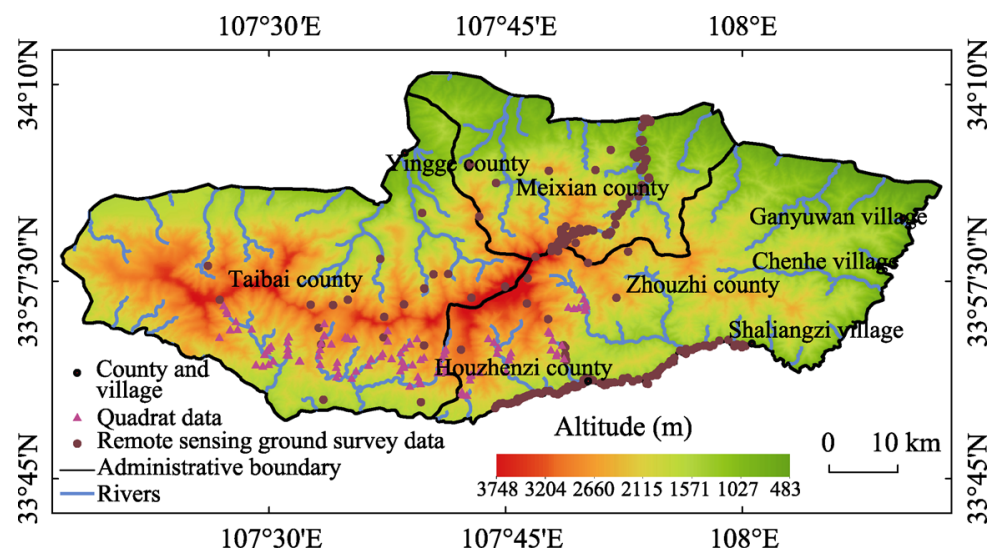

Figure 1 Outline of Taibai Mountain and the distribution of ground survey samples

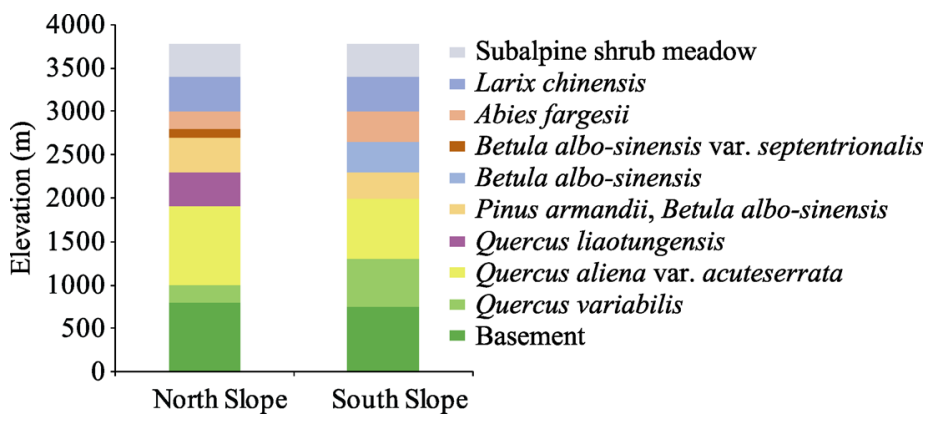

Figure 2 Mountain altitudinal belts of Taibai Mountain (after Fang and Gao, 1963; Li, 2007) 


\section{Data and methods}

\subsection{Datasets}

High-resolution remote sensing data, Digital Surface Model (DSM) data, remote sensing ground survey data and quadrat data are used to compile the 1:50,000 vegetation type map of Taibai Mountain in this paper.

(1) High-resolution remote sensing data

Remote sensing data used for vegetation classification in this paper include 4 GF-2 images, 13 GF-1 images and 21 ZY-3 images (Table 1). The spatial resolution of GF-2 images is $0.8 \mathrm{~m}$. The enhancement resolution of 10 panchromatic and 11 multispectral ZY-3 images is $2 \mathrm{~m}$, and these ZY-3 images cover the whole Taibai Mountain. The spatial resolution of GF-1 images is also $2 \mathrm{~m}$. In addition, there are 5 GF-1 multi-spectral images with a $16 \mathrm{~m}$ spatial resolution. These images from January 2015 to February 2018 cover four seasons of spring, summer, autumn and winter and provide a guarantee for the extraction of vegetation types.

Table 1 Remote sensing images of Taibai Mountain

\begin{tabular}{|c|c|c|c|c|c|}
\hline Sensor & Time & Resolution & Sensor & Time & Resolution \\
\hline \multirow{4}{*}{ GF2 } & August 3, 2017 & $0.8 \mathrm{~m}$ & \multirow{19}{*}{ ZY3 } & September 28, 2017 & $2 \mathrm{~m}$ \\
\hline & September 7, 2017 & $0.8 \mathrm{~m}$ & & August 5, 2017 & $2 \mathrm{~m}$ \\
\hline & September 7, 2017 & $0.8 \mathrm{~m}$ & & August 31, 2016 & $2 \mathrm{~m}$ \\
\hline & August 3, 2017 & $0.8 \mathrm{~m}$ & & February 3, 2018 & $2 \mathrm{~m}$ \\
\hline \multirow{13}{*}{ GF1 } & August 28, 2016 & $2 \mathrm{~m}$ & & February 8, 2018 & $2 \mathrm{~m}$ \\
\hline & November 30, 2016 & $2 \mathrm{~m}$ & & September 28, 2017 & $2 \mathrm{~m}$ \\
\hline & October 28, 2017 & $2 \mathrm{~m}$ & & August 5, 2017 & $2 \mathrm{~m}$ \\
\hline & February 12, 2017 & $2 \mathrm{~m}$ & & August 31, 2016 & $2 \mathrm{~m}$ \\
\hline & August 28, 2016 & $2 \mathrm{~m}$ & & February 3, 2018 & $2 \mathrm{~m}$ \\
\hline & November 30, 2016 & $2 \mathrm{~m}$ & & February 8, 2018 & $2 \mathrm{~m}$ \\
\hline & October 28, 2017 & $2 \mathrm{~m}$ & & July 14, 2017 & $2 \mathrm{~m}$ \\
\hline & February 12, 2017 & $2 \mathrm{~m}$ & & September 22, 2016 & $2 \mathrm{~m}$ \\
\hline & August 8, 2017 & $16 \mathrm{~m}$ & & September 22, 2016 & $2 \mathrm{~m}$ \\
\hline & January 20, 2015 & $16 \mathrm{~m}$ & & November 10, 2016 & $2 \mathrm{~m}$ \\
\hline & October 1, 2015 & $16 \mathrm{~m}$ & & November 4, 2017 & $2 \mathrm{~m}$ \\
\hline & July 1, 2017 & $16 \mathrm{~m}$ & & January 13, 2017 & $2 \mathrm{~m}$ \\
\hline & February 12, 2017 & $16 \mathrm{~m}$ & & July 14, 2017 & $2 \mathrm{~m}$ \\
\hline \multirow[t]{2}{*}{ ZY3 } & November 4, 2017 & $2 \mathrm{~m}$ & & September 22, 2016 & $2 \mathrm{~m}$ \\
\hline & January 13, 2017 & $2 \mathrm{~m}$ & & November 10, 2016 & $2 \mathrm{~m}$ \\
\hline
\end{tabular}

(2) Ground survey data

Ground survey data used in this paper are remote sensing ground survey data and quadrat data. From June 8 to June 15, 2018, our research team carried out a field survey in Taibai Mountain and acquired 286 remote sensing ground survey data by GPS sampling and the Ovey Interactive Map. These ground survey data include geographical location, vegetation type groups, vegetation types, vegetation formations/sub-formations and other information of the sample points. Additionally, a total of 181 quadrat data were collected from the com- 
prehensive investigation project of National Nature Reserve in Taibai Mountain, Shaanxi province.

(3) Digital surface model (DSM) data

The 1:10,000 DSM data of Taibai Mountain (resolution $10 \mathrm{~m}$ ) was generated from ZY-3 satellite images. DSM data in this paper is mainly used to extract the slope, slope direction, altitude and surface coverage data of fine scale, and it is also used to construct terrain constraint factors.

(4) Vegetation map data of Taibai Mountain

The vegetation map data include the 1:1,000,000 Vegetation Map of China in 2000 and the Vegetation Distribution Map of Taibai Mountain compiled by the "Comprehensive Investigation Project of Taibai Mountain National Nature Reserve, Shaanxi Province" in 2006. These earlier vegetation maps can provide qualitative references and comparative studies for the classification of vegetation types.

\subsection{Methods}

(1) Classification system of 1:50,000 vegetation type map of Taibai Mountain in Qinling Mountains

The classification system of 1:50,000 vegetation type map of Taibai Mountain in Qinling Mountains still adopts the classification system of 1:1,000,000 Vegetation Map of China, but it refines the formation group, formation and sub-formations according to the actual situation. The classification system of the 1:1,000,000 Vegetation Map of China uses six classification levels, namely vegetation type group, vegetation type, vegetation sub-type, formation group, formations and sub-formation. The legend system is divided into four levels: Level 1 includes 11 vegetation type groups (coniferous forest, coniferous and broad-leaved mixed forest, broad-leaved forest, shrub, desert, grassland, herbosa, meadow, swamp, alpine vegetation and cultivated vegetation); Level 2 includes 53 vegetation types and 2 vegetation sub-types, a total of 55 types; Level 3 includes 11 formation groups, 571 formations and 4 sub-formations, a total of 586 types, it is the basic units of the map; Level 4 includes 29 formations, 244 sub-formations, a total of 273 types, it is the lowest-level mapping units.

In the 1:1,000,000 Vegetation Map of China, the vegetation of Taibai Mountain was divided into 6 vegetation type groups (coniferous forest, broad-leaved forest, shrub, herbosa, meadow and cultivated vegetation), 11 vegetation types and sub-types, and 24 vegetation formations and sub-formations. In this paper, vegetation of Taibai Mountain was also divided into six vegetation type groups (coniferous forest, coniferous and broad-leaved mixed forest, broad-leaved forest, shrub, meadow and cultivated vegetation), but 12 vegetation types and sub-types, and 52 vegetation formation groups, formations and sub-formations (Table 2). According to the field survey of Taibai Mountain and other relevant research, there is a certain proportion of coniferous and broad-leaved mixed forest in Taibai Mountain, while the herbosa does not appear in a large area at present, so the classification of vegetation type groups in this paper is different from that of the 1:1,000,000 Vegetation Map of China. Correspondingly, the classifications of vegetation types and vegetation formations are different, especially vegetation formation groups, formations and sub-formations in this paper increase by 28 types compared with that shown on the 1:1,000,000 Vegetation Map of China. 
Table 2 Vegetation classification system of Taibai Mountain

\begin{tabular}{|c|c|c|}
\hline Vegetation type groups & Vegetation types, sub-types & $\begin{array}{c}\text { Vegetation formation groups, formations, } \\
\text { sub-formation }\end{array}$ \\
\hline \multirow{3}{*}{ Meadows } & Kobresia, forbs alpine meadows & $\begin{array}{l}\text { Polygonum macrophyllum } D . D \text {, } \\
\text { Polygonum viviparum meadow }\end{array}$ \\
\hline & \multirow{2}{*}{ Temperate grasses, forbs meadows } & Carex lanceolata, grasses meadow \\
\hline & & Carex lanceolata, forbs meadow \\
\hline \multirow{6}{*}{ Shrubs } & \multirow{2}{*}{$\begin{array}{l}\text { Subalpine deciduous broad-leaved } \\
\text { shrubs }\end{array}$} & Salix cupularis shrub \\
\hline & & Spiraea mongolica shrub \\
\hline & \multirow{4}{*}{$\begin{array}{l}\text { Subalpine evergreen leather-leaved } \\
\text { shrubs }\end{array}$} & Rhododendron lapponicum shrub \\
\hline & & Rhododendron clementinae subsp. Aureodorsale shrub \\
\hline & & Rhododendron purdomii shrub \\
\hline & & Rhododendron capitatum shrub \\
\hline \multirow{7}{*}{ Coniferous forests } & \multirow{2}{*}{ Temperate coniferous forests } & Platycladus orientalis forest \\
\hline & & Pinus tabuliformis forest \\
\hline & \multirow{3}{*}{$\begin{array}{l}\text { Subtropical and tropical montane } \\
\text { coniferous forests }\end{array}$} & Abies fargesii, Larix chinensis forest \\
\hline & & Abies fargesii forest \\
\hline & & Larix chinensis forest \\
\hline & \multirow{2}{*}{ Subtropical coniferous forests } & Pinus armandii, Larix chinensis forest \\
\hline & & Pinus armandii forest \\
\hline \multirow{16}{*}{ Mixed forests } & \multirow{10}{*}{$\begin{array}{l}\text { Temperate coniferous and deciduous } \\
\text { broad-leaved mixed forests }\end{array}$} & $\begin{array}{l}\text { Platycladus orientalis, Quercus aliena var. acuteser- } \\
\text { rata forest }\end{array}$ \\
\hline & & Platycladus orientalis, Quercus variabilis forest \\
\hline & & $\begin{array}{l}\text { Pinus tabuliformis, Quercus serrata var. brevipetiolata } \\
\text { forest }\end{array}$ \\
\hline & & $\begin{array}{l}\text { Pinus tabuliformis, Quercus aliena var. acuteserrata } \\
\text { forest }\end{array}$ \\
\hline & & Pinus tabuliformis, quercus variabilis forest \\
\hline & & Abies fargesii, Betula albo-sinensis forest \\
\hline & & $\begin{array}{l}\text { Abies fargesii, Betula albo-sinensis var. septentrion- } \\
\text { alis forest }\end{array}$ \\
\hline & & Pinus armandii, Quercus spinosa forest \\
\hline & & $\begin{array}{l}\text { Pinus armandii, Quercus serrata var. brevipetiolata } \\
\text { forest }\end{array}$ \\
\hline & & Pinus armandii, Betula albo-sinensis forest \\
\hline & \multirow{6}{*}{$\begin{array}{l}\text { Subtropical montane coniferous and } \\
\text { deciduous broad-leaved mixed forests }\end{array}$} & Pinus armandii, Quercus baronii forest \\
\hline & & Pinus armandii, Quercus liaotungensis forest \\
\hline & & $\begin{array}{l}\text { Pinus armandii, Betula albo-sinensis var. septentrion- } \\
\text { alis forest } \\
\text { Pinus armandii, Quercus aliena var. acuteserrata } \\
\text { forest }\end{array}$ \\
\hline & & Pinus armandii, Fagus longipetiolata forest \\
\hline & & Pinus armandii, Populus davidiana forest \\
\hline & & Pinus armandii, Quercus variabilis forest \\
\hline \multirow{4}{*}{ Broadleaf forests } & \multirow{4}{*}{$\begin{array}{l}\text { Temperate deciduous broad-leaved } \\
\text { forests }\end{array}$} & Betula albo-sinensis, Quercus liaotungensis forest \\
\hline & & Betula albo-sinensis forest \\
\hline & & Quercus baronii forest \\
\hline & & Quercus liaotungensis forest \\
\hline
\end{tabular}


(Continued)

\begin{tabular}{|c|c|c|}
\hline Vegetation type groups & Vegetation types, sub-types & $\begin{array}{c}\text { Vegetation formation groups, formations, } \\
\text { sub-formation }\end{array}$ \\
\hline & & Betula albo-sinensis var. septentrionalis forest \\
\hline & & $\begin{array}{l}\text { Quercus aliena var. acuteserrata, Pterocarya stenop- } \\
\text { tera forest }\end{array}$ \\
\hline & & $\begin{array}{l}\text { Quercus aliena var. acuteserrata, Quercus acutissima } \\
\text { forest }\end{array}$ \\
\hline & & $\begin{array}{l}\text { Quercus aliena var. acuteserrata, Populus davidiana } \\
\text { forest }\end{array}$ \\
\hline & & Quercus aliena var. acuteserrata forest \\
\hline & & Populus davidiana, Quercus liaotungensis forest \\
\hline & & Populus davidiana forest \\
\hline & & $\begin{array}{l}\text { Quercus variabilis, Quercus aliena var. acuteserrata } \\
\text { forest }\end{array}$ \\
\hline & & Quercus variabilis, Populus simonii forest \\
\hline & & Quercus variabilis, Ulmus pumila forest \\
\hline & & Quercus variabilis forest \\
\hline \multirow[t]{2}{*}{ Cultivated plants } & $\begin{array}{l}\text { Dry farming of three matures in two } \\
\text { years or double cropping in one year }\end{array}$ & $\begin{array}{l}\text { Triticum aestivum, Zea mays Linn. Sorghum bicolor } \\
\text { (L.) Moench }\end{array}$ \\
\hline & Deciduous orchard & Castanea mollissima BL., Juglans regia L. \\
\hline
\end{tabular}

(2) Remote sensing interpretation method for vegetation types in Taibai Mountain

Remote sensing interpretation of vegetation types in Taibai Mountain was carried out according to the following process: firstly, based on the 1:10,000 DSM data and the distribution heights of mountain altitudinal belts (MABs) of Taibai Mountain, three types of terrain factors of the main ridge line, the slope direction and the elevations of MABs in the study area were extracted, and the terrain constraint factors with MABs information were generated by the above three types of terrain factors (Figure 3). Secondly, assisted by the terrain constraint factors with MABs information, 6 vegetation type groups were analyzed and extracted. Then, the vegetation formation groups, formations and sub-formations were extracted according to their distribution heights (upper and lower limits of MABs) and image characteristics. Finally, vegetation types and sub-types were assigned according to the regional geographical characteristics, climatic conditions of the vegetation formations and characteristics of the vegetation type groups.

With the assistance of terrain constraint factors, the vegetation type groups were extracted by visual interpretation according to the spectral features and texture features of high-resolution remote sensing images of $0.8 \mathrm{~m}$ and $2 \mathrm{~m}$ in Taibai Mountain (Figure 4). Firstly, shrub and meadow are distributed at the top of the mountain above $3400 \mathrm{~m}$, and they have distinct texture features in summer images. Secondly, it is the division of shrubs and coniferous forest belts. Larix chinensis forest is located below the shrub belt, and the two vegetation types have different spectral and texture characteristics in summer and autumn images, which are easy to be distinguished from each other. Thirdly, it is the division of coniferous forest, broad-leaved forest and coniferous \& broad-leaved mixed forest. The broad-leaved forest of Taibai Mountain is a temperate deciduous broad-leaved forest, its upper boundary is composed of Betula albo sinensis and Betula albo-sinensis var. septentrionalis forest, while the lower boundary of coniferous forest is Pinus armandii forest or 
Abies fargesii forest; coniferous \& broad-leaved mixed forests are mainly composed of the Abies fargesii and Betula albo-sinensis forest, the Pinus armandii and Betula albo-sinensis forest, and the Pinus armandii and Quercus liaotungensis forest. With high-resolution images in winter, broad- leaved forest, coniferous forest and coniferous \& broad-leaved mixed forest have obviously different spectral characteristics, so the boundaries among of them can be accurately identified from winter pseudo-color images. In addition, cultivated vegetation mostly distributed in the foothill belt below $800 \mathrm{~m}$ has different texture and structure characteristics from those of natural vegetation.

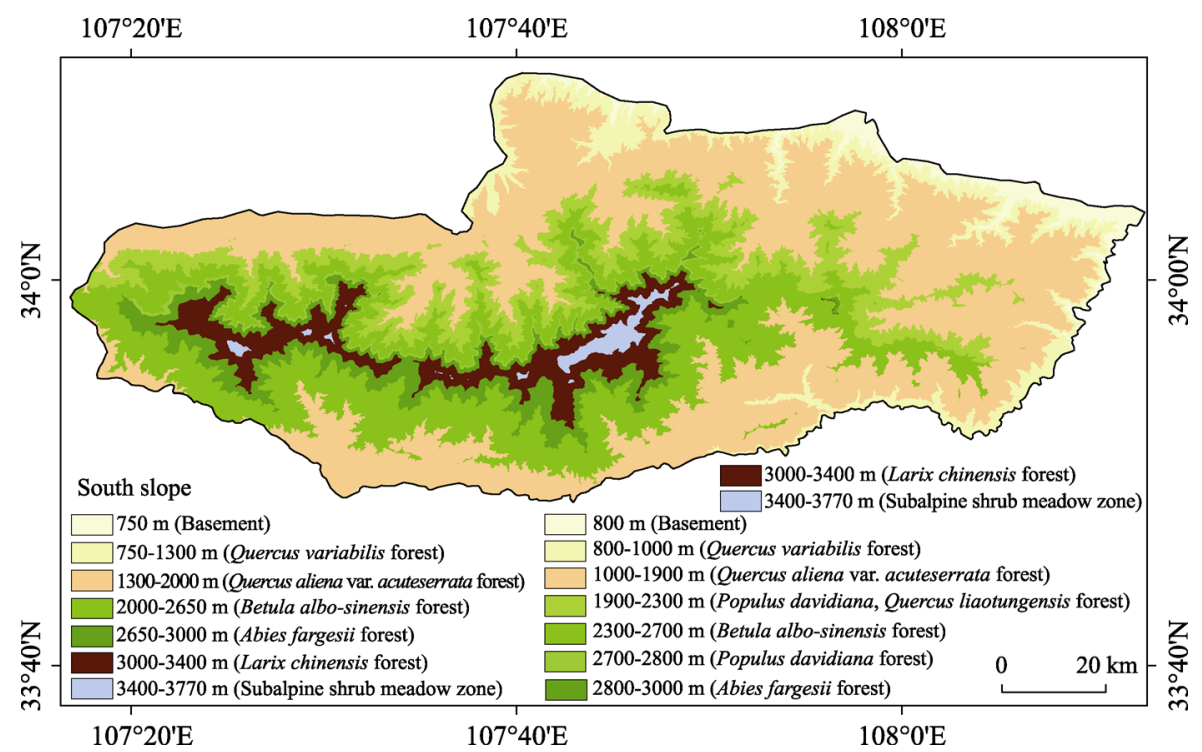

Figure 3 Terrain constraint factor map with mountain altitudinal belts information

Based on the classification of vegetation type groups, vegetation formation groups, formations and sub-formations in Taibai Mountain were further divided. Pinus armandii, Abies fargesii, Larix chinensis are main vegetation formations of the coniferous vegetation type groups in Taibai Mountain, and they have distinct different distribution heights and ranges according to the terrain constraint factors and have different spectral and texture characteristics in the autumn and winter images. Particularly, Abies fargesii forest has very special spectral characteristics on pseudo-color image, thus its distribution range can be accurately extracted (Figure 4). Pinus armandii and Larix chinensis forests are respectively located below and above the Abies fargesii forest. Therefore, through the division of Abies fargesii forest, the three types of coniferous vegetation formations can be accurately divided. The deciduous broad-leaved forests in Taibai Mountain are composite of Quercus variabilis forest, Quercus aliena var. acuteserrata fortest, Betula albo-sinensis forest and Betula albo-sinensis var. septentrionalis forest up the foothills. On the north slope, Quercus liaotungensis forest is distributed below the Betula albo-sinensis forest. The classification of vegetation formations in various broad-leaved forests is the difficulty of this paper. Besides the remote sensing images, the terrain constraint factors, ground survey data and original vegetation type maps data are useful auxiliaries for classification.

Finally, the spatial distribution characteristics of other vegetation formations were extracted and determined according to remote sensing ground survey data and quadrat surveys. 
On the basis of the classification of the above vegetation type groups and main vegetation formations, the multi-spectral remote sensing images of $2 \mathrm{~m}$ and $16 \mathrm{~m}$ in different seasons were used to analyze the spectral characteristics, NDVI and other characteristics of each vegetation formations with seasons. All vegetation formations were extracted by visual interpretation.

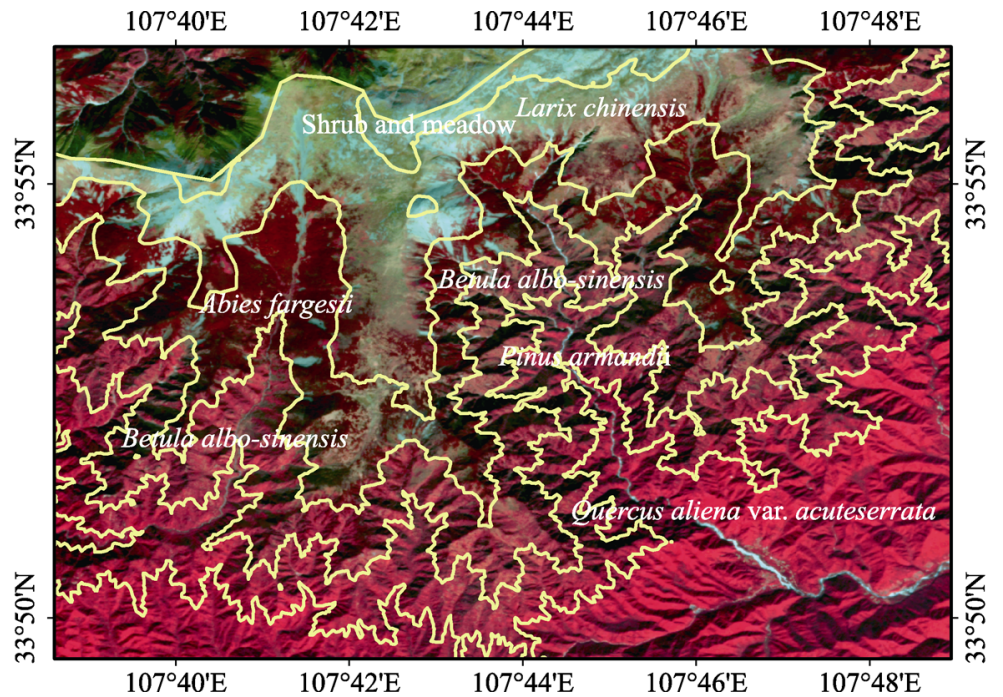

Figure 4 Terrain constraint factor map overlaying with remote sensing images (South slope, Time: 2017/02/12; Resolution: 2 m; Band combination: 432 pseudo-color)

\section{Results and analysis}

(1) Classification results of vegetation type groups

The classification results of vegetation type groups are shown in Figure 5. The vegetation type groups in Taibai Mountain with distinct vertical zonality are composed of cultivated vegetation, broad-leaved forest, coniferous \& broad-leaved mixed forest, coniferous forest, shrub and meadow successively from foothills to top; the cultivated vegetation does not appear on the south slope of the study area. The broad-leaved forest area is about $722.17 \mathrm{~km}^{2}$, the coniferous forest area is about $493.44 \mathrm{~km}^{2}$, and the coniferous \& broad-leaved mixed forest area is $720.40 \mathrm{~km}^{2}$, accounting for $91.58 \%$ of the whole study area.

(2) Classification results of vegetation formation groups, formations and sub-formations

In this experiment, there are 52 formation groups, formations and sub-formations in Taibai Mountain (Table 1). The results of remote sensing visual interpretation are shown in Figure 5. Among them, the seven main formations from foothills to top are Quercus variabilis forest, Quercus aliena var. acuteserrata fortest, Quercus liaotungensis forest, Betula albo-sinensis forest, Pinus armandii forest, Abies fargesii forest and Larix chinensis forest, and also show obvious vertical zonality. Quercus liaotungensis forest only appears on the north slope, and its distribution altitude is often the same as that of Pinus armandii forests. The above seven main formations account for about $60 \%$ of the total area.

(3) Classification results of vegetation types and sub-types

Among 12 vegetation types and sub-types (Table 1), temperate deciduous broad-leaved forest is the largest vegetation type, accounting for $34.16 \%$ of the total area of the experi- 
ment. The second is the montane coniferous forest \& deciduous broad-leaved mixed forest in subtropical zone, accounting for $28.19 \%$ of the total area. The third is the montane coniferous forest in subtropical and tropical zones, accounting for $14.07 \%$ of the total area. Subtropical coniferous forest (mainly composed of Pinus armandii forest) accounts for $8.60 \%$ of the total area. The above four vegetation types and sub-types account for $85.02 \%$ of the total area, and they also show obvious vertical distribution characteristics: they are temperate deciduous broad-leaved forest, subtropical montane coniferous forest \& deciduous broad-leaved mixed forest, subtropical coniferous forest and subtropical \& tropical montane coniferous forest from foothills to top. From the composition of vegetation types and sub-types in this study, it shows that the proportion of temperate vegetation types and sub-types in Taibai Mountain is higher than that of subtropical and tropical vegetation types and sub-types, and the composition and distribution of vegetation show the transition characteristics from subtropical zone to temperate zone.

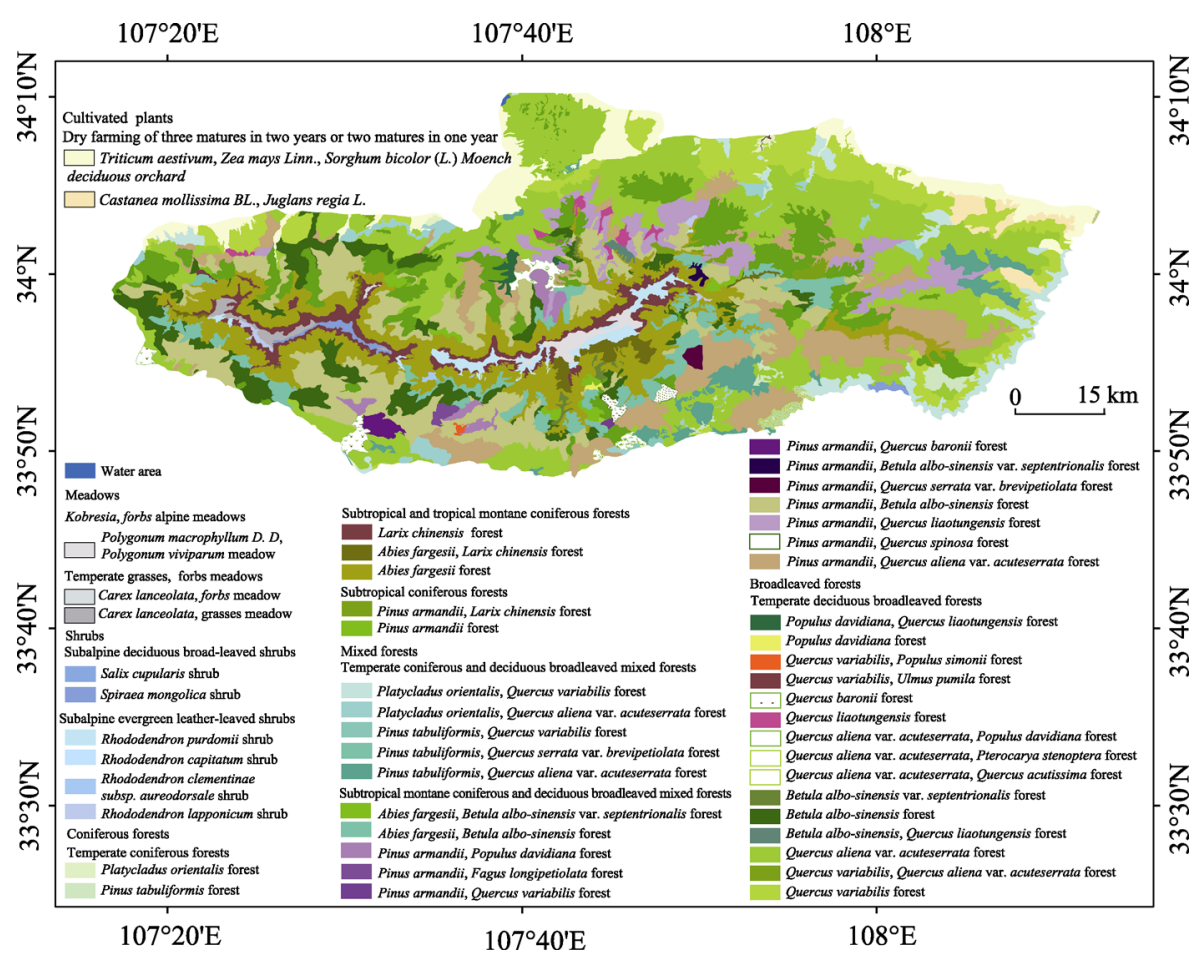

Figure 5 Vegetation type map of Taibai Mountain

\section{Conclusions and discussion}

\subsection{Conclusions}

(1) The above experimental studies show that the information of mountain altitudinal belts (MABs) and vegetation geographical distribution could effectively support remote sensing classification and mapping of mountain vegetation. Firstly, with the assistant of terrain constraint factors with MABs information, vegetation type groups of Taibai Mountain can be extracted accurately from the multi-temporal remote sensing images. Secondly, based 
on the classification of six vegetation type groups, seven main vegetation formations, such as Pinus armandii forest, Abies fargesii forest, Larix chinensis forest and Betula albosinensis forest, can be distinguished and extracted according to terrain constraint factors and spectral characteristics of remote sensing image. Thirdly, other vegetation formations can be further determined according to the MABs, the relationship between vegetation formations, ground survey data and previous vegetation maps. Finally, vegetation types and sub-types are assigned according to the regional geographical characteristics, climatic conditions of the vegetation formations and the characteristics of the vegetation type groups.

(2) The process of complication of 1:50,000 vegetation type map based on remote sensing images is: interpretation of vegetation type-group $\rightarrow$ interpretation of vegetation formation groups, formations and subformations $\rightarrow$ interpretation and classification of vegetation types \& subtypes, which is a combination method of top-down method and bottom-up method, not the top-down or the bottom-up classification according to the level of mapping units. In the classification system of vegetation type map, the vegetation type group is the highest classification unit, which is mainly divided according to the morphological characteristics of the constructive species communities, but also contains certain ecological content. Vegetation type and sub-type are higher classification unit between vegetation type group and vegetation formation group, formation and sub-formation. Vegetation type is composed of the constructive species with the same or similar life type and the plant communities with consistent ecological relationship and hydrothermal conditions. For zonal vegetation, vegetation type refers to the product of a certain climatic zone, and for intrazonal vegetation, it refers to the special habitat conditions of the communities. Vegetation sub-type is an auxiliary unit of vegetation type and reflects the difference of climate subzone, or the differences in vegetation lamellar structure caused by the differences of certain landform and matrix conditions. Therefore, the classification of vegetation types and sub-types is mainly based on the environmental conditions of the plant communities. Vegetation formation group, formation and sub-formation has the same or similar constructive species or co-constructed species and it is the basic mapping units of vegetation type maps. Thus, in the vegetation classification based on remote sensing imagines, for this three-level vegetation classification mapping units, only two of them (vegetation type group, and vegetation formation group, formation and sub-formation) can be interpreted according to image features such as texture, structure and spectral features combined with the auxiliary information such as MABs. While, the vegetation type and sub-type cannot be directly interpreted by image features, it needs to be classified according to types of vegetation type groups and the climatic conditions of vegetation formation groups, formations and sub-formations. Therefore, the basic remote sensing interpretation and mapping process for typical mountains is to extract vegetation type groups first, then extract vegetation formation groups, formations and sub-formations within the vegetation type groups, and finally assign the vegetation types and sub-types according to climate condition of the constructed species.

\subsection{Discussion}

(1) Some vegetation formations are still difficult to distinguish from others in this experiment. First of all, it is difficult to distinguish Quercus variabilis forest from Quercus 
aliena var. acuteserrata forest on the image feature, although the Quercus aliena var. acuteserrata forest is distributed above the Quercus variabilis forest. If the ground survey data are limited, it would be difficult to find out the precise distribution boundary between them only based on MABs. Secondly, it is also difficult to distinguish Quercus liaotungensis forest from Quercus aliena var. acuteserrata fortest in the north slope according to image characteristics, and a lot of ground survey data are needed to extract Quercus liaotungensis forest correctly. Finally, there are also some uncertainties for the classification of coniferous $\&$ broad-leaved mixed forests.

(2) The experimental study in this paper was still carried out by visual interpretation and auxiliary supervised classification. In the following research, we will study and establish a multi-source vegetation classification knowledge database that integrates various geoscience information (MABs information, terrain constraint factors, etc.), vegetation geography and previous vegetation classification information. According to knowledge transfer method, a set of vegetation remote sensing classification methods based on prior knowledge will be constructed (Wu et al., 2014) and an integrated extraction method of automatic extraction and manual interactive interpretation for vegetation types will be realized through the in-depth application of the decision tree algorithm (Li et al., 2013), multi-example learning theory and multivariate detection (Nielsen, 2007). At present, remote sensing information extraction has developed from traditional visual interpretation and semi-automatic interpretation to automatic extraction with expert knowledge. Artificial intelligence methods such as self-organizing neural network, fuzzy logic inference and support vector machine have been widely applied to the extraction of vegetation and other thematic elements (Luo et al., 2017). With the support of computer technology, all kinds of geographic auxiliary knowledge and prior knowledge can be effectively combined with remote sensing computing models through knowledge transfer method, active learning or deep learning method, so as to achieve more accurate information extraction of remote sensing.

\section{References}

Chen B Q, Li X P, Xiao X M et al., 2016. Mapping tropical forests and deciduous rubber plantations in Hainan Island, China by integrating PALSAR 25-m and multi-temporal Landsat images. International Journal of Applied Earth Observation and Geoinformation, 50: 117-130.

Chinese Vegetation Map Editorial Committee (CVMEC), Chinese Academy of Sciences, 2000. Atlas of 1:1000000 Chinese Vegetation. Beijing: Science Press. (in Chinese)

Chinese Vegetation Map Editorial Committee (CVMEC), Chinese Academy of Sciences, 2007. Vegetation and Its Geographical Patterns in China: Instructions for Vegetation Maps of the People's Republic of China. Beijing: Geology Press. (in Chinese)

Demir B, Bovolo F, Bruzzone L et al., 2013. Updating land-cover maps by classification of image time series: A novel change-detection-driven transfer learning approach. IEEE Transactions on Geoscience and Remote Sensing, 51(1): 300-312.

Fang Z, Gao S Z. Vegetation altitudinal belts on the north and south slopes of Taibai Mountain in Qinling Mountains. Series of Plant Ecology and Geobotany, 1963, (1): 162-163. (in Chinese)

Hou X Y, Ma R Z, 1956. Vegetation-Soil Zoning Map of China. Beijing: Map Press. (in Chinese)

Hou X Y, Sun S Z, Zhang J W et al., 1979. Vegetation Map of the People's Republic of China (1: 4000000). Beijing: Map Press. (in Chinese) 
Hu B, Ju H B, Liu Hua et al., 2017. Combining multiple classifiers based on evidence theory for large scale vegetation types classification by remote sensing images. Forestry Research, 30(2): 194-199. (in Chinese)

Jia M M, Ren C Y, Liu D W et al., 2014. Object-oriented forest classification based on combination of HJ-1 CCD and MODIS NDVI data. Acta Ecologica Sinica, 34(24): 7167-7174. (in Chinese)

Lei G B, Li A N, Tan J B et al., 2016. Forest types mapping in mountainous area using multi-source and multi-temporal satellite images and decision tree models. Remote Sensing Technology and Application, 31(1): 31-41. (in Chinese)

Li H N. Study on plant species diversity and vertical distribution patterns on the north slope of Taibai Mountain [D]. Xi'an: Shaanxi Normal University, 2007. (in Chinese)

Li Z, Yang X M, Meng F et al., 2013. LULC classification based on random forest with the aid of phonological feature. Remote Sensing Information, 28(6): 48-55. (in Chinese)

Liu J Y, 1996. China Resources and Environment Remote Sensing Macro Survey and Dynamic Research. Beijing: China Science and Technology Press. (in Chinese)

Liu J Y, Liu M L, Zhuang D F et al., 2003a. Study on spatial pattern of land-use change in China during 1995-2000. Science in China Series D: Earth Sciences, 46(4): 373-384.

Liu J Y, Zhang Z X, Zhuang D F et al., 2003b. A study on the spatial-temporal dynamic changes of land-use and driving forces analyses of China in the 1990s. Geographical Research, 22(1): 1-12. (in Chinese)

Liu J Y, Zhang Z X, Xu X L et al., 2010. Spatial patterns and driving forces of land use change in China during the early 21 st century. Journal of Geographical Sciences, 20(4): 483-494.

Liu X F, Pan Y Z, Zhu X F et al., 2015. Spatiotemporal variation of vegetation coverage in Qinling-Daba Mountains in relation to environmental factors. Acta Geographica Sinica, 70(5): 705-716. (in Chinese)

Luo J C, Wu G J, Li J L et al., 2017. Spatial-spectral Recognition of Remote Sensing. Beijing: Sciences Press. (in Chinese)

Marsetic A, Ostir K, Fras M K, 2015. Automatic orthorectification of high-resolution optical satellite images using vector roads. IEEE Transactions on Geoscience and Remote Sensing, 53(11): 6035-6047.

Nielsen A A, 2007. The regularized iteratively reweighted MAD method for change detection in multi-and hyperspectral data. IEEE Transaction on Image Processing, 16(2): 463-478.

Qian C S, 1956. Draft of Vegetation Regionalization in China. Beijing: Science Press. (in Chinese)

Wu T J, Luo J C, Xia L G et al., 2014. An automatic sample collection method for object-oriented classification of remotely sensed imageries based on transfer learning. Acta Geodaetica et Cartographica Sinica, 43(9): 908-916. (in Chinese)

Xia L G, 2011. Research on automatic classification of remote sensing images coupled with "graph-spectrum" characteristics [D]. Hangzhou: Zhejiang University of Technology. (in Chinese)

Yue M, 2015. Vegetation altitudinal belts of Qinling Mountains. Forests and Human Beings, 2: 76-81. (in Chinese)

Zhang J J, Zhu W B, Zhao F et al., 2018. Spatial variations of terrain and their impacts on landscape patterns in the transition zone from mountains to plains: A case study of Qihe River Basin in the Taihang Mountains. Science China Earth Sciences, 2018, 48(4): 476-486.

Zhang X D, Zhu W B, Zhang J J et al., 2018. Phenology of forest Qihe River Basin in the Taihang Mountains. Science China Earth Sciences, 48(4): 476-486. (in Chinese) vegetation and its response to climate change in the Funiu Mountains. Acta Geographica Sinica, 73(1): 41-53. (in Chinese) 